\title{
Disease Screening
}

National Cancer Institute

\section{Source}

National Cancer Institute. Disease Screening. NCI Thesaurus. Code C15419.

The use of any device, marker, or other means for the purpose of detecting the presence of disease, usually in asymptomatic individuals. 